\title{
НОВЫЕ ПОЛИМЕРНЫЕ ТРУБЫ ДЛЯ ПРОМЫШЛЕННОГО ПРИМЕНЕНИЯ
}

\author{
К.А. Евсеева, В.В. Битт, В.И. Скребнев, Е.В. Калугина
}

Научно-исследовательский институт ООО «Группа ПОЛИПЛАСТИК», ул. Генерала Дорохова, 14, с. 1, г. Москва, Российская Федерация, 119530.

E-mail: kseniya.evseeva@polyplastic.ru,bitt@polyplastic.ru,vladimir.skrebnev@polyplastic.ru, kalugina@polyplastic.ru

В статье представлены результаты применения полимерных композиционных материалов (ПКМ) со специальными свойствами (трудногорючесть, электропроводность, износостойкость) при изготовлении покрытий труб для кабельных каналов, пульпопроводов и различных видов промышленной канализации. Приведены технические характеристики трудногорючих и электропроводных ПКМ. Обсуждены методы и результаты испытаний по показателям горючести применительно к полимерному материалу и к изделию, а такжже натурных испытаний трубы Электропайп ОС при коротком замыкании на объекте МОЭК. Описаны требования, предъявляемые к трубам в горнодобываюцей промышленности. В итоге разработана трехслойная конструкция трубы Мультипайn АC-ОС: на основную несущую трубу из ПЭВП наносится оболочка из трудногорючей композиции, а сверху на эту оболочку тонкий слой антистатического материала. Испьтания на искробезопасность показали, что возгорания трубы не происходит. При воздействии пламени горелки на внешний антистатический слой происходит его прогорание и коксование трудногорючей композиции, что приводит прекращению горения. Одним из основных требований к пульпопроводам является стойкость к гидроабразивному износу. Выбор материала для внутреннего слоя трубы осуществляли по результатам динамического механического анализа полиолефинов и термоэластопластов различного состава. Работоспособность труб в условиях интенсивного гидроабразивного износа гидросмесями хвостов обогащения железных руд, влияние на интенсивность износа концентрации, дисперсности и скорости гидросмесей исследовали на специальной установке и показали, что многослойная напорная труба с ТЭП-покрытием характеризуется высокой стойкость к гидроабразивному износу.

Ключевые слова: трудногорючесть, электропроводность, износостойкость, полимерные трубы, термостабильность

\section{NEW POLYMER PIPES FOR INDUSTRIAL APPLICATIONS}

\author{
K.A. Evseeva, V.V. Bitt, V.I. Skrebnev, E.V. Kalugina
}

Materials Research Center OOO «POLYPLASTIC GROUP», Generala Dorokhova str., 14/1, Moscow, Russian Federation, 119530

E-mail: kseniya.evseeva@polyplastic.ru,bitt@polyplastic.ru, vladimir.skrebnev@polyplastic.ru, kalugina@polyplastic.ru

The article presents the results of the use of polymer composite materials (PCM) with special properties (incombustibility, electrical conductivity, wear resistance) in the manufacture of pipe coatings for cable channels, pulp pipelines and various types of industrial sewerage. The technical characteristics of non-flammable and electrically conductive PCM are given. Methods and results of tests on the indicators of flammability in relation to the polymer material and to the product, as well as full-scale tests of the Electropipe OS with a short circuit at the MOEK facility are discussed. The requirements for pipes in the mining industry are described. As a result, a threelayer design of the Multipipe AS-OS was developed: a shell of a difficult-to-burn composition is applied to the main carrier pipe from HDPE, and a thin layer of antistatic material is applied on 
top of this shell. Tests for intrinsic safety have shown that the pipe does not ignite. When the burner flame is exposed to the external antistatic layer, it burns out and coking of the difficult-to-burn composition occurs, which leads to the termination of flame. One of the main requirements for pulp pipelines is resistance to waterjet wear. The material for the inner layer of the pipe was selected based on the results of dynamic mechanical analysis of polyolefins and thermoplastics composites. The operability of pipes under conditions of intensive waterjet wear by hydraulic mixtures of iron ore dressing tailings, the effect on the wear intensity of the concentration, dispersion and speed of hydraulic mixtures was studied on a special installation and showed that a multilayer pressure pipe with a TPE coating is characterized by high resistance to waterjet wear.

Key words: flameability, electrical conductivity, wear resistance, plastic pipes, heat stability

Для цитирования:

Евсеева К.А., Битт В.В., Скребнев В.И., Калугина Е.В. Новые полимерные трубы для промышленного применения. Рос. хим. ж. (Ж. Рос. хим. об-ва). 2021. Т. LXV. № 3. С. 85-90

For citation:

Evseeva K.A., Bitt V.V., Skrebnev V.I., Kalugina E.V. New polymer pipes for industrial applications. Ros. Khim. Zh. 2021. V. 65. N 3. P. 85-90

Интенсивное развитие полимерных трубопроводных систем для промышленного применения в России отмечено в последнее десятилетие как следствие развития отдельных областей техники (кабельная, горно-добывающая промышленность), а также готовность отрасли переработки пластмасс обеспечить потребности в полимерных композиционных материалах (ПКМ) со специальными свойствами (трудногорючесть, электропроводность, износостойкость) [1]. В таблице 1 и 2 представлены свойства трудногорючего ПКМ в рецептуре которого использованы интумесцентные антипирены.

Основными показателями, характеризующими горючесть полимерных композиций, являются: стойкость к горению, стойкость к воспламенению раскаленной проволокой и кислородный индекс.

Однако для решения о применимости материала для изготовления изделия, будь то трубы для прокладки кабелей, шахтные трубы для газо- или водоотвода или пульпопроводы проводятся дополнительные испытания готового изделия - трубы на стойкость к распространению горения при одиночной или групповой прокладке по ГОСТ 53313 и по показателям «группа горючести» ГОСТ 30244, «воспламеняемости» по ГОСТ 30402 и дымообразующей способности ГОСТ12.1.044. В промышленных трубопроводах допускают применение труб с группой горючести и воспламеняемости не ниже Г2 и В2, Т2 соотв. Испытание проводят на образцах в виде пластин размером $1000 \times 190$ мм, изготовленных из трубы. Продолжительность воздействия пламени 10 мин, температура пламени $1200{ }^{\circ} \mathrm{C}$. Для групп Г1-ГЗ не допускается образование горящих капель. Требование норматива для группы Г1: температура дымовых газов $\leq 135{ }^{\circ} \mathrm{C}$, степень повреждения образца после испытания $\leq 65 \%$ по длине и $\leq 20 \%$ по массе.

Технические характеристики трудногорючего ПКМ

Таблица 1

\begin{tabular}{|c|c|c|}
\hline Показатель & Метод & Результат \\
\hline 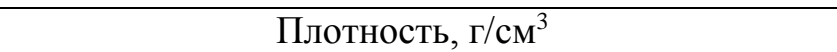 & ASTMD-792 & 1,14 \\
\hline Водопоглощение, \% & ASTM D-570 & 0,02 \\
\hline ПТР, $190{ }^{\circ} \mathrm{C} / 5$ кг & ГОСТ 11645 & $1,0 \div 4,0$ \\
\hline \multicolumn{3}{|c|}{ Физико-механические свойства } \\
\hline Модуль упругости при растяжении, МПа & ГОСТ 11262 & 1024 \\
\hline Предел текучести, МПа & ГОСТ 11262 & 17,6 \\
\hline Относительное удлинение при разрыве, \% & ГОСТ 11262 & 6,56 \\
\hline \multicolumn{3}{|l|}{ Горючесть } \\
\hline Коэффициент дымообразования, м²/кг & ГОСТ 24632 & $<300$ \\
\hline Кислородный индекс, \% & ГОСТ 21793 & 38 \\
\hline Категория горючести (образцы толщиной 1,6 мм) & UL 94 & $\mathrm{VO}$ \\
\hline Раскаленная проволока, ${ }^{\circ} \mathrm{C}$ & ГОСТ 27483 & 960 \\
\hline
\end{tabular}


Технические характеристики трудногорючего ПКМ

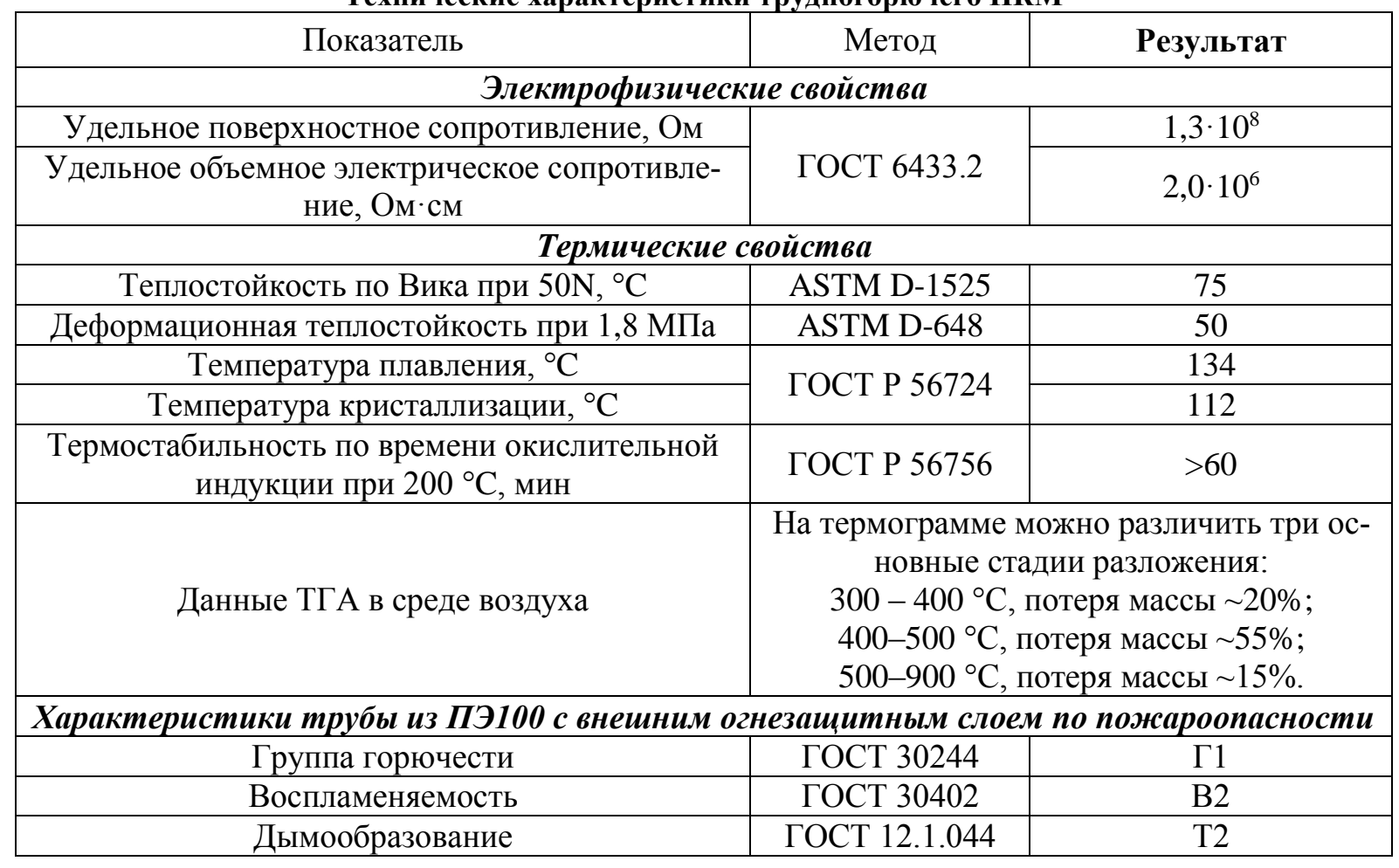

При выносе образца из зоны горения (удалении горелки) материал должен мгновенно затухать. На рис. 1 представлены фотографии образцов до (а) и после (б) испытания.

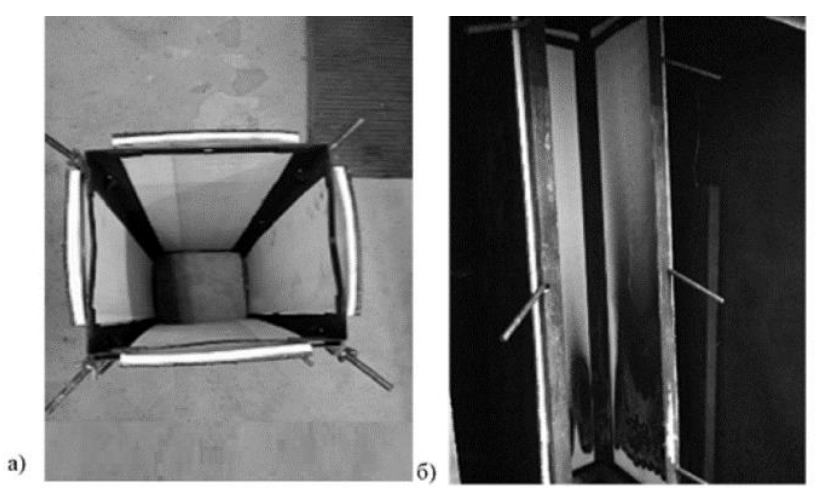

Рис. 1. Испытание образцов из трубы Электропайп ОС на стойкость к распространению горения образцы в сборе а), образцы после испытания б)

При воздействии пламени на поверхности образуется плотная карбонизированная «корка» огнестойкого слоя, вокруг которой материал, который не был в прямом контакте с огнем практически не видоизменяется. Слой кокса при горении защищает от возгорания основную трубу, препятствует проникновению кислорода и при выносе образца из зоны горелки, затухает.
Никакие лабораторные испытания не дают полного представления о поведении трубы в реальных аварийных условиях короткого замыкания (КЗ), поскольку остается неясным, выдержит ли труба давление взрыва при КЗ, повышение температуры до более $1000{ }^{\circ} \mathrm{C}$, произойдет ли возгорание, удастся ли вытащить кабель после короткого замыкания, насколько изменится (упадет) жесткость трубы после аварии. НИИ ПОЛИПЛАСТИК совместно с МОЭК были проведены натурные испытания труб коротким замыканием в кабеле, помещенном в трубу Электропайп ОС, в условиях, максимально приближенных к эксплуатационным. В ходе испытаний произвели КЗ в кабеле с изоляцией из сшитого полиэтилена АПвПуг 1х120/35 10 кВ с напряжением 10000 В и током 12000 А. После испытания кабель легко извлекли из трубы, а трубу разрезали для изучения физико-химических и механических свойств материалов конструкции. При КЗ (воздействия открытого огня) происходит коксообразование на поверхности трубы (аналогично рис. 1). Термостабильность базового ПЭВП и трудногорючей композиции практически не изменилась, что важно для долговременной эксплуатации трубы. Судя по полученным результатам, высокотемпературное воздействие КЗ практически не сказалось на величине прочностных свойств материалов трубы. 
Если для производства кабельных каналов к основным требованиям механических характеристик добавляется требование трудногорючести, то трубы для шахт должны кроме трудногорючести характеризоваться еще и антистатическими свойствами, причем, показатель объемного электрического сопротивления ПКМ должен быть не выше $10^{5}$ Ом·см, что определяется условиями эксплуатации. При эксплуатации полимерного трубопровода в шахтах может произойти случайное возникновение искрового разряда [2]. Для исключения возникновения подобных явлений необходимо обеспечить отвод электростатических зарядов путем увеличения проводимости, например, использовать трубопровод со специальным токопроводящим слоем или обработать поверхность антистатиком. Электропроводность дисперснонаполненных полимерных композиционных материалов (ПКМ) определяется формированием пространственной структуры, образованной из контактирующих частиц наполнителя. [4] Однако для получения технологичного композита с высоким значением токопроводимости в полимерную матрицу необходимо вводить значительное количество наполнителя, что может негативно повлиять на механические свойства готовых изделий. Выбор материала для конкретного применения зависит от возможности достичь компромисс между рядом различных требований, например, к механическим показателям с сохранением определенного уровня электрической проводимости, легкости переработки, пожаробезопасности и стоимости. Электрические свойства полученных композиций оценивали по показателям: удельное поверхностное $\left(\rho_{\mathrm{s}}\right)$ и удельное объемное $\left(\rho_{\mathrm{v}}\right)$ электрическое сопротивление в соответствии с ГОСТ 6433.2 и сопротивлению изоляции [3]. Для достижения совокупности оптимальных значений электрической проводимости и механической прочности тестировали различные типы саж (печная или менее эффективная ацетиленовая), которые уже при введении 20-35 \% масс. образуют электропроводящую структуру, однако технический углерод как наполнитель имеет тоже ряд своих недостатков, например, сажи способны адсорбировать кислород, что приводит к ухудшению структурности [5-8], а агломерирование частиц приводит к снижению физико-механических свойств ПКМ. Авторами [9] было показано, что введение в полимеры сажи с большой удельной поверхностью, высокой пористостью, малым раз- мером частиц и высокой структурностью позволяет получить электропроводные полимерные композиции с относительно невысоким содержанием сажи. Были протестированы ПКМ Pre-Elek TR 11820 (PREMIX) и Баско ПН-Ф/02, предназначенные для изготовления токопроводящих полимерных изделий, а также суперконцентрат Pre-Elek PE 1296. По результатам экспериментов, все композиции являются электропроводными $\left(\rho_{\mathrm{v}}=10^{3}-10^{4} \mathrm{OM} \cdot \mathrm{cm}\right.$, $\rho_{\mathrm{s}}=10^{4}-10^{5}$ Ом) характеризуются достаточно высокой термостабильностью по времени окислительной индукции (70-80 мин) и технологичностью $\left(П Т P_{190^{\circ} \mathrm{C}, 5.0 \text { кг }}=0,2-3,0\right.$ г/10 мин) и могут применяться при изготовлении оболочки трубы. Однако, эти композиции не являются трудногорючими, а дополнительное введение электропроводной сажи в трудногорючий ПКМ приводит к снижению физико-механических характеристик и технологичности. Изготовить из такого материала оболочку трубы практически невозможно. Техническим решением было изготовление трубы трехслойной конструкции: «несущая» труба из ПЭ100 -промежуточный слой трудногорючая оболочка из ПКМ антистатическая композиция ПЭ с электропроводной сажей (рис. 2 - фотография трубы Мультипайп $\mathrm{AC}-\mathrm{OC}$ с внешней антистатической трудногорючей оболочкой).

На рис. 2 представлены фотографии трубы при тестировании на горючесть. При воздействии пламени горелки на внешний антистатический слой трубы происходит его прогорание и коксование трудногорючего ПКМ. Электропроводность внешней оболочки оценивали по показателю сопротивление изоляции (табл. 3).
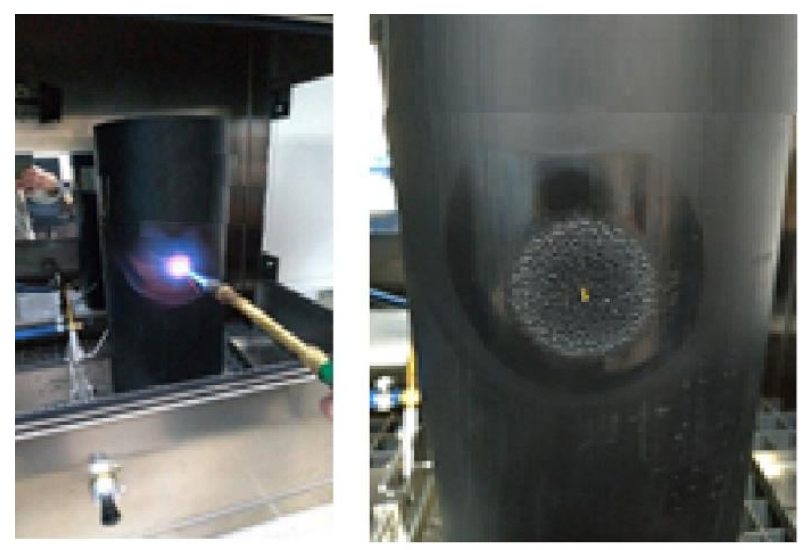

Рис. 2. Оценка горючести трубы Мультипайп ОС-АС. Воздействие пламенем в течение 2 мин

Трубы Электропайп ОС серийно выпускают на предприятиях ООО «Группа ПОЛИПЛАСТИК» на протяжении более 5 лет. Тестирование 
труб Мильтипайп АС-ОС выявило необходимость придания изделию дополнительного свойства - повысить стойкость внутреннего (несущего) слоя трубы к гидроабразивному износу. В настоящее время практически все горно-обогатительные комбинаты (ГОК) в России и странах постсоветского пространства применяют стальные пульпопроводы, но в связи с низкой износостойкостью стальные трубы достаточно быстро выходят из строя. Для увеличения срока службы пульпопроводов применяют армированные резиновые шланги, а также трубы, футерованные термопластичными полиуретанами и резинами. Производство резины - дорогой и энергозатратный процесс, а термопластичные полиуретаны (ТПУ) имеют высокую стоимость и практически на производятся в РФ. Решением проблемы может быть применение полиэтиленовых труб с внутренним соэкструзионным слоем из термопластичных эластомеров (ТЭП) - ближайшего аналога резин. Сравнительные испытания износостойкости различных полимерных материалов подробно описаны в [10]. Поскольку под действием гидроабразивного потока материал подвергается многократным кратковременным деформациям, приводящим в последствии к снижению его усталостной прочности, то для изучения поведения материала при гидроабразивном износе целесообразно применение динамического механического анализа (ДМА) $[11,12]$. Как правило, температура эксплуатации пульпопровода ограничивается плюс $60^{\circ} \mathrm{C}$. В области температур $0-100{ }^{\circ} \mathrm{C}$ на графике температурной зависимости модуля динамических потерь полиолефинов наблюдается пик (температурный переход) - отклик материала на механическое воздействие (рис. 3), что подтверждено низкой стойкостью ПЭ и ПП к гидроабразивному износу.

Определение сопротивления изоляции трубы Мультипайп ОС-АС

Таблица 3

\begin{tabular}{|c|c|c|c|}
\hline \multirow{2}{*}{ Место приложения электродов } & \multicolumn{3}{|c|}{ Сопротивление изоляции, кОм } \\
\cline { 2 - 4 } & $100 \mathrm{~B}$ & $250 \mathrm{~B}$ & $1000 \mathrm{~B}$ \\
\hline $\begin{array}{c}\text { Внутренняя поверхность-внутрен- } \\
\text { няя поверхность }\end{array}$ & $\mathrm{OL}^{*}$ & $\mathrm{OL} *$ & $\mathrm{OL}^{*}$ \\
\hline $\begin{array}{c}\text { Внешняя поверхность с разных } \\
\text { сторон от сварного шва }\end{array}$ & 150 & 590 & 470 \\
\hline $\begin{array}{c}\text { Внешняя поверхность с одной сто- } \\
\text { роны от сварного шва }\end{array}$ & 60 & 150 & 100 \\
\hline
\end{tabular}

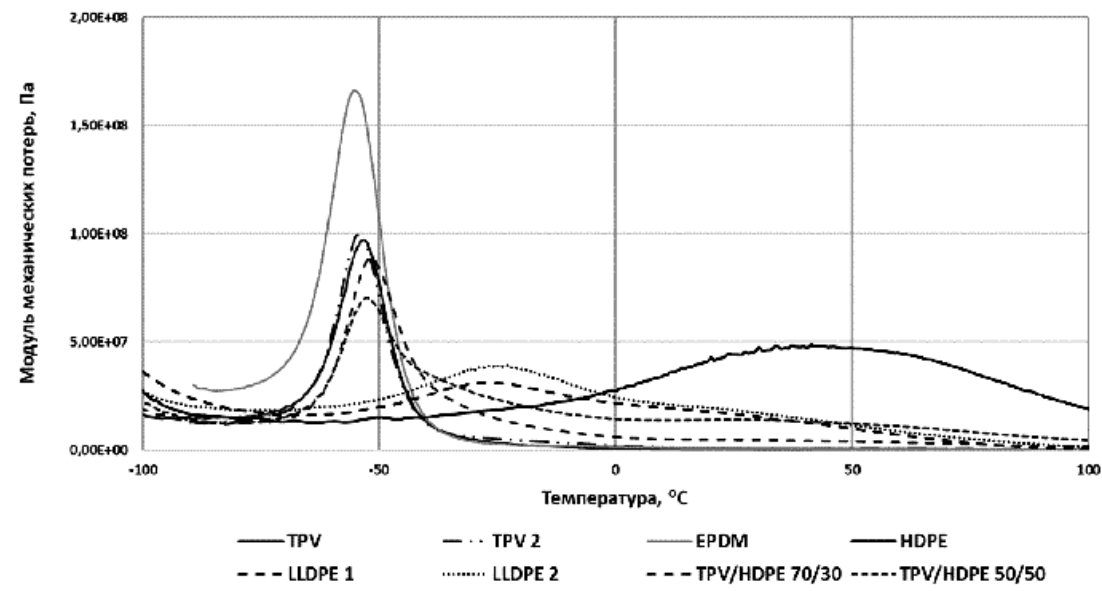

Рис. 3. Зависимость модуля механических потерь от температуры для различных базовых полимеров и ПКМ

Модуль динамических потерь резины (EPDM) и ТЭП, в состав которых входит СКЭПТ, в данном диапазоне температур приближается к нулю (рис. 3). С увеличением содержания ПЭВП в смесях с ТЭП ин- тенсивность пика увеличивается в диапазоне положительных температур, причем величины этих пиков коррелируют с составом композиции - содержанием ПЭВП (рис. 3). Работоспособность труб в условиях интенсивного гидроабразивного износа гидросмесями хвостов обогащения железных руд, влияние на интенсивность износа концентрации, дисперсности и скорости гидросмесей исследовали на специальной установке в лаборатории кафедры транспортно-технологических процессов и машин Санкт-Петербургского Горного Университета. Проведенные исследования показали, что после покачивания гидросмеси объемом более $5700 \mathrm{M}^{3}$ и общей продолжительности эксперимента более 600 ч образцы многослойной напорной трубы с ТЭП-покрытием показали высокую стойкость к гидроабразивному износу по сравнению с 
трубой из ПЭ 100 и трубой из стали Ст3сп. Длительный инкубационный период разрушения оболочки из ТЭП обуславливает долговечность труб. Системы трубопроводов выпускаются под торговыми марками МУЛЬТИПАЙП ИС, МУЛЬТИПАЙП ИС ПРОТЕКТ с наружной оболочкой для защиты от механических повреждений, УФ излучения и перегрева трубопровода при прокладке на открытом воздухе.

Трубы МУЛЬТИПАЙП ИС-ОС-АС рекомендованы на объектах с повышенными требованиями пожарной безопасности с внутренним износостойким слоем и наружным огнезащитным и антистатическим покрытием, что подтверждено результатами сертификационных испытаний пожаро- и искробезопасности.

\section{ЛИТЕР А Т УР А}

1. Бобович Б.Б. Неметаллические конструкционные материалы: учебное пособие. М.: МГИУ. 2009. 384 с.

2. Отставнов А.А. Особенности борьбы со статическим электричеством, возникающим на полимерных трубопроводах. СОК. 2006. №8. С. 20-24.

3. Богородицкий Н.П., Пасынков В.В., Тареев Б.М. Электротехнические материалы. Л.: Энергия. 1977. 352 с.

4. Блайт Э.Р., Блур Д. Электрические свойства полимеров. М.: Физматлит. 2008. $373 \mathrm{c.}$

5. Гуль В.Е., Шенфиль Л.В. Электропроводящие полимерные композиции. М.: Химия. 1984. 240 с

6. Крыжановский В.К., Бурлов В.В. Технические свойства полимерных материалов. СПб.: Профессия. 2005. 248 с.

7. Саввинова М.Е., Коваленко Н.А. Переработка углеродосодержащих композиций на основе полиолефинов. Наука и образование. 2006. № 1 (41). 82-84 с.

8. Лущеейкин Г.А. Методы исследования электрических свойств полимеров. М.: Химия. 1988. 6-23 с.

9. Василенок Ю.И. Предупреждение статической электризации полимеров. Л.: Химия. 1981. 209 с.

10. Белкин С.А., Битт В.В., Скребнев В.И., Калугина Е.В. Композиционные полимерные материалы в технологических промышленных трубопроводах и кабелезащите. Тез. докл. XIV Научн. Конф. Технологии и материалы для экстремальных условий. М.: МЦАИ РАН. 2019. С. 95-103.

11. Тагер А.А. Физико-химия полимеров. Издание второе. М.: Химия. 1968. $536 \mathrm{c}$.

12. Klaus Friedrich. Erosive wear of polymers surfaces by steel ball blasting. Journal of Materials Science. 1986. V. 21 (9). P. 3317-3332. DOI: 10.1007/BF00553375.

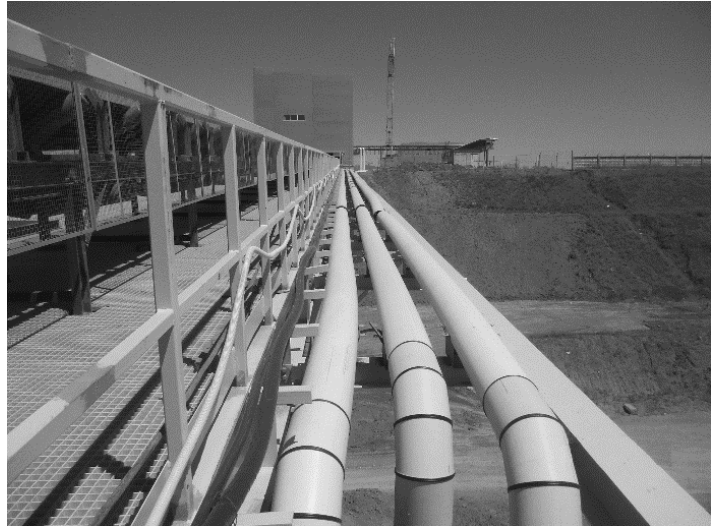

Рис. 4. Гремячинский ГОК. Пульпопровод на основе труб МУЛЬТИПАЙП ИС ПРОТЕКТ

\section{REFERENCES}

1. Bobovich B.B. Nemetallicheskie konstrukcionnye materialy [Non-metallic engineering materials]. Moscow, Moskovskii gosudarstvennyi industrial'nyi universitet, 2009. $384 \mathrm{p}$.

2. Otstavnov A.A. Osobennosti bor'by so staticheskim elektrichestvom, voznikayushchim na polimernykh truboprovodakh [Specific measures to control static electricity in polymer pipelines]. Santekhnika, otoplenie, konditsionirovanie. 2006. N 8. P. 20-24.

3. Bogoroditskii N.P., Pasynkov V.V., Tareev B.M. Elektrotekhnicheskie materialy [Electrotechnical materials]. Leningrad, Energiya Publ. 1977. 352 p.

4. Blait E.R., Blur D. Elektricheskie svoistva polimerov [Electrical properties of polymers]. Moscow, Fizmatlit Publ. 2008. 373 p.

5. Gul' V.E., Shenfil' L.V. Elektroprovodiashchie polimernye kompozitsii [Electrically conductive polymer compositions]. Moscow, Khimiia Publ. 1984. 240 p.

6. Kryzhanovskii V.K., Burlov V.V. Tekhnicheskie svoistva polimernykh materialov [Technical properties of polymer materials]. Saint Petersburg, Professiia Publ. 2005. 248 p.

7. Cavvinova M.E., Kovalenko N.A. Pererabotka uglerodosoderzhashchikh kompozitsii na osnove poliolefinov [Processing of polyolefin based carbon-containing compositions]. Nauka i obrazovanie. 2006. N 1 (41). P. 82-84.

8. Lushcheikin G.A. Metody issledovaniia elektricheskikh svoistv polimerov [Methods for studying the electrical properties of polymers]. Moscow. Khimiia Publ. 1988. P. 6-23.

9. Vasilenok Iu.I. Preduprezhdenie staticheskoi elektrizatsii polimerov [Prevention of static electrification of polymers]. Leningrad, Khimiia Publ. 1981. 209 p.

10. Belkin S.A., Bitt V.V., Skrebnev V.I., Kalugina E.V. Kompozitsionnye polimernye materialy $\mathrm{v}$ tekhnologicheskikh promyshlennykh truboprovodakh i kabelezashchite [Composite polymer materials with reference to industrial pipelines and cable ducts]. Tekhnologii i materialy dlia ekstremal'nykh uslovii. Materialy XIV vserossiiskoi nauchnoi konferentsii. Moscow, Mezhvedomstvennyi tsentr analiticheskikh issledovanii v oblasti fiziki, khimii i biologii pri Prezidiume Rossiiskoi akademii nauk. 2019. P. 95-103.

11. Tager A.A. Fiziko-khimiia polimerov [Physical chemistry of polymers]. 2nd ed. Moscow, Khimiia Publ. 1968. 536 p.

12. Klaus Friedrich. Erosive wear of polymers surfaces by steel ball blasting. Journal of Materials Science. 1986. V. 21 (9). P. 3317-3332. DOI: 10.1007/BF00553375.

Поступила в редакичию (Received) 01.08.2021

Принята к опубликованию (Accepted) 03.09.2021 